\title{
Well ARMed and FiRM \\ Diversification of mortgage loans for homeowners
}

\section{Rasmussen, Kourosh Marjani; Zenios, Stavros A.}

Published in:

The Journal of Risk

Publication date:

2007

Link back to DTU Orbit

Citation (APA):

Rasmussen, K. M., \& Zenios, S. A. (2007). Well ARMed and FiRM: Diversification of mortgage loans for homeowners. The Journal of Risk, 10, 67-84.

\section{General rights}

Copyright and moral rights for the publications made accessible in the public portal are retained by the authors and/or other copyright owners and it is a condition of accessing publications that users recognise and abide by the legal requirements associated with these rights.

- Users may download and print one copy of any publication from the public portal for the purpose of private study or research.

- You may not further distribute the material or use it for any profit-making activity or commercial gain

- You may freely distribute the URL identifying the publication in the public portal

If you believe that this document breaches copyright please contact us providing details, and we will remove access to the work immediately and investigate your claim. 
Well ARMed and FiRM:

Diversification of mortgage loans for homeowners

by

Kourosh M. Rasmussen and Stavros A. Zenios

Working Paper 06-02

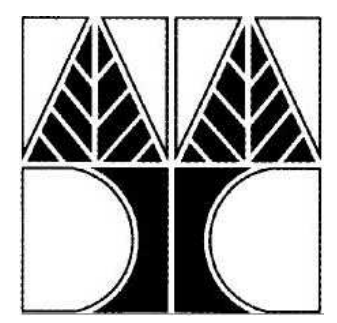

\author{
HERMES Center of Excellence \\ on Computational Finance \& Economics \\ University of Cyprus \\ P.O. Box 20537, 1678 Nicosia, CYPRUS
}




\section{HERMES Center of Excellence on Computational Finance \& Economics}

The HERMES Center on Computational Finance and Economics at the University of Cyprus has been selected by the European Commission as a European Center of Excellence in 2000 . The Center faculty, graduate students, and visitors pursue a broad research agenda that focuses on optimal financial decision making from both the supply side (financial institutions) and the demand side (households and institutional investors). Emphasis is placed on the challenges created for both sides by the globalization and innovations of the financial markets, especially for the economies of pre-accession States as they move towards harmonization with European Union.

The work of the Center is divided in five major areas. The first deals with enterprise wide risk management and the development of both innovative methodologies and decision support tools. The second deals with the saving and borrowing behavior of households and their portfolio choices. The third deals with empirical studies of capital markets and the information they reveal for the prediction of bankruptcy events and the management of credit risk. The fourth deals with real options, their valuation, and their use in coping with an uncertain world. The fifth deals with issues surrounding the performance of financial institutions in delivering quality services.

Data-driven theoretical modeling, empirical analysis, and the use of computations are the cornerstones of the disciplinary approaches of the Center's activity, that brings together researchers from finance, economics, accounting, management sciences, mathematics and computer science. Research is basic, yet relevant to this important sector of economic activity.

The Center fosters a community of scholars, practitioners, and graduate students whose interests support the mission of the Center. Close collaboration with industry ensures that the Center's research remains not only cutting-edge in pursuit of academic excellence, but is also relevant to financial institutions, in their quest for competitive excellence. If you would like to know more about the Center or join in its activities please let us know of your interest and visit our Web site at http://www.hermes.ucy.ac.cy/

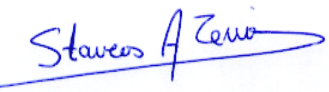

Stavros A. Zenios

Director 


\title{
Well ARMed and FiRM: Diversification of mortgage loans for homeowners
}

\author{
Kourosh M. Rasmussen* Stavros A. Zenios ${ }^{\dagger}$
}

May 2006

\author{
Working Paper 06-02 \\ HERMES Center on Computational Finance and Economics \\ School of Economics and Management \\ University of Cyprus \\ Nicosia, CYPRUS.
}

\begin{abstract}
Individual homeowners are offered today a wide range of mortgage options for financing the purchase of a house. Usually, homeowners are also granted an option to repay the mortgage loan, and in some countries - such as Denmark - it is particularly efficient to do so as market conditions change or the homeowner's situation warrants it. And while, traditionally, a single mortgage loan would serve borrower needs, today it appears that a portfolio of loans may satisfy much better the mortgage needs of the individual and his or her appetite for risk. In this paper we develop a model for the diversification of mortgage loans of a homeowner and apply it to data from the Danish market. Even in the presence of mortgage origination costs it is shown that most risk averse homeowners will do well to consider a diversified portfolio of both fixed (FRM) and adjustable (ARM) rate mortgages. This is particularly so if one takes, unavoidably, a long term perspective in financing the purchase of a home through a mortgage loan.
\end{abstract}

\footnotetext{
*Technical University of Denmark, Lyngby, Denmark. kmr@imm.dtu.dk

${ }^{\dagger}$ HERMES Center on Computational Finance and Economics, University of Cyprus, Nicosia, Cyprus and The Wharton Financial Institutions Centre, University of Pennsylvania, Philadelphia, USA. zenioss@ucy.ac.cy
} 


\section{Introduction}

What is in a name? Everything is in the name, the marketing guru will tell us, and the names used to pitch the hottest subset of the old-fashioned mortgages tell a lot: Interest-Only (I-O), OptionARM and Pick-a-Payment have been added to the traditional shopping list of fixed (FRM) or adjustable (ARM) rate mortgages.

In essence all these mortgage products aim at satisfying the same underlying need of borrowers: offering them a loan to achieve the immediate home purchasing goals, with payment terms that can be adapted as the family earnings change - usually with an upward adjustment especially for young home buyers - while offering some protection from market changes to both borrowers and lenders. The issue, especially for first time buyers, has been one of trading off the lower rate and payment on an ARM with the interest rate risk of the ARM, or going for the higher initial payments of a FRM and lower risk when the FRM is kept to maturity. With an I-O the initial payments can be reduced substantially, but future payments will increase significantly when the interest-only clause expires and principal payments must be made, especially if there have been significant changes in interest rates since the loan was issued.

According to some surveys (Real Estate Center at the Wharton School, University of Pennsylvania, "Could risky mortgage lending practices prick the housing bubble?", Web newsletter, 2002) innovative mortgage products account for half of the new mortgages written in the USA, up from less than $10 \%$ in 2001. The innovations in the Danish market have not been as exotic as their US counterparts, but they have been particularly simple and efficient to promote. The seven specialized mortgage banks that operate in Denmark fund the loans by issuing bonds in the capital markets. The terms of the bonds are identical to the mortgage loan they fund, with the mortgage bank adding a markup on the market yield of bonds with maturity comparable to the loan. Given the readily available information of market yields all banks offer the same markup rate, and this mechanism is equivalent to the borrower issuing his or her own bonds. Furthermore, all borrowers pay the same rate on the same type of loan issued on a given date. (This is possible, even accounting for differences in credit worthiness of the borrowers, as most loans require a $20 \%$ down payment which adequately covers a wide range of credit risky borrowers. However, borrowers with very poor credit or without initial endowment are not served in this market.)

Given the simplicity with which market rates are transformed into mortgage loans, on any given day a borrower can be offered a range of fixed-rate mortgages with 15,20 or 30 year maturity, and adjustable rate mortgages with adjustment periods ranging from one to ten years, and these products reach a wide market segment. The total amount of mortgage loans issued 
in Denmark - this includes origination of new loans plus the refinancing of old loans - in 2005 totals almost 100 billion EURO. This represents a record increase of $25 \%$ from the year before, and corresponds to half of the Danish gross domestic product. Fixed and adjustable rate mortgages account for $50 \%$ of the mortgage market each. Innovative products such as I-O and ARM with a cap are quite popular. About $30 \%$ of the total ARMs in the market come with a cap, while about $30 \%$ of the total amount of mortgage loans in the private and summer house market are I-O.

The refinancing activity in this market is also noteworthy. About one third of all outstanding loans, for a total of 70 billion EURO, were refinanced in 2005. The issue of new loans reached 20 billion EURO, corresponding to a growth of $10 \%$ to the total amount of mortgage loans in the Danish market which sets a new record.

Some form of protection from either market changes or changes in family conditions - job loss, births, deaths or divorce - comes in the form of an early prepayment option. Additional protection from interest rate risk is offered through caps on the rate adjustment of ARMs or with the purchase of fixed rate mortgages. But then one has to deal with the higher rates associated with a FRM and accept the risk that rates will decline while payments on the loan remain locked. Furthermore, in the Danish market, early termination of a FRM requires prepayment of the mortgage at prevailing market prices which represents significant interest rate risk for homeowners with issued loans with prices below par, except those few who keep the mortgage to maturity.

\section{Are there diversification benefits from portfolios of mortgage loans?}

In the context introduced above it is somewhat surprising that the question of diversification of homeowner mortgage loan has not received to date any attention. This is primarily due to the transaction costs involved in obtaining more than one mortgage loans - mortgage origination fees in Denmark stand currently at 300 EUR. But still, in the efficient Danish market there has been an interest in selling more than one product to each homeowner. Indeed, it can be easily observed that a combination of mortgage loans could provide lower average total payments during the life of a mortgage, and with less variability as interest rates change. Figure 1 illustrates the changes in total payment for FRMs and an ARM with increasing interest rates. It is seen from this figure that the sensitivity of FRMs and ARMs to interest rate changes have opposite signs, and hence a properly balanced portfolio of both types of loans could provide better protection than either mortgage alone. 

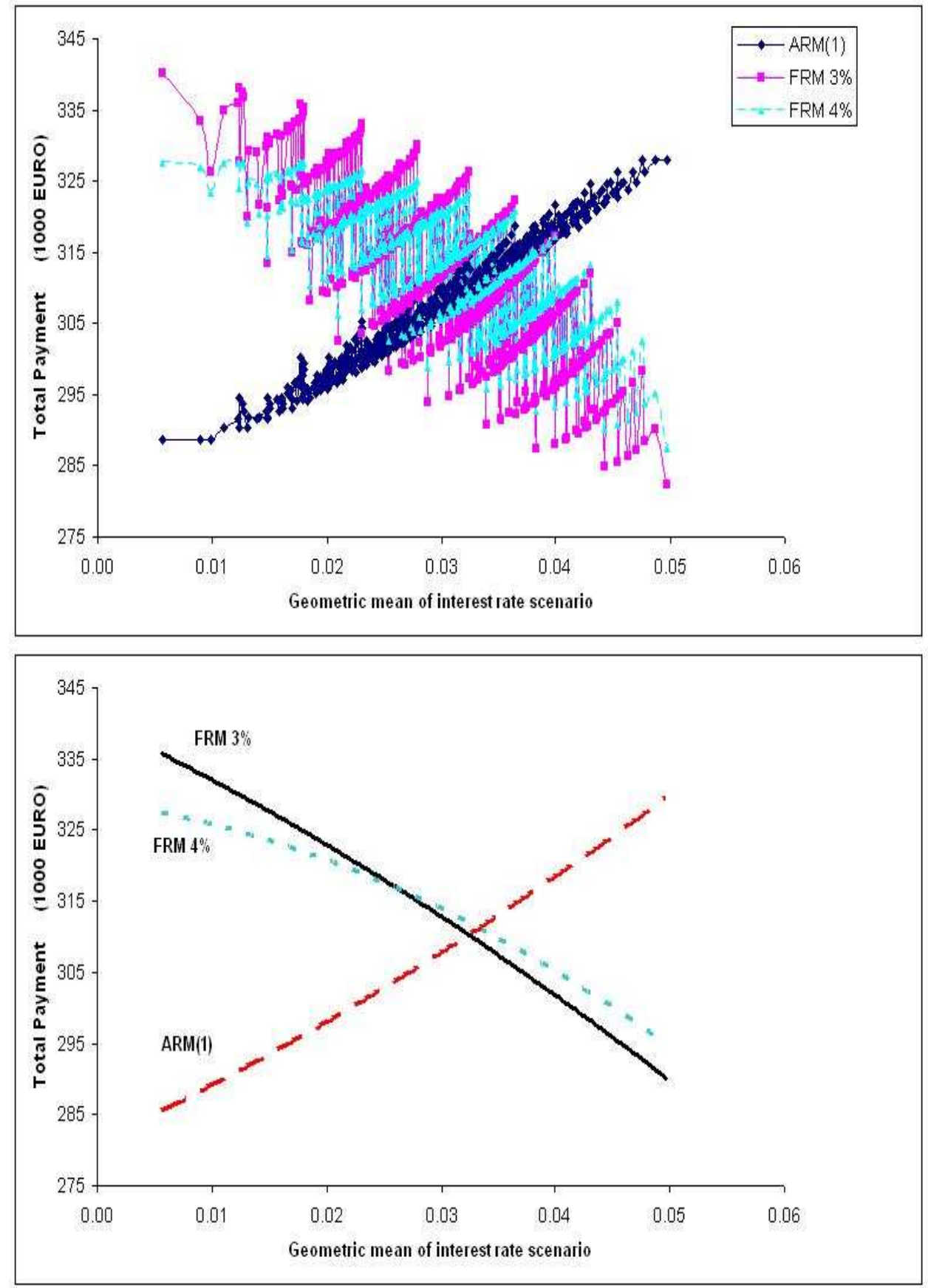

Figure 1: The total expected payment of 30-year fixed (3\% and 4\% FRM) and adjustable $(\operatorname{ARM}(1)$ with annually adjusted rates) rate mortgages have opposite sensitivities to changing interest rates. (Top figure shows all simulated data for a six year planning horizon; bottom figure smooths the data using second order approximations.) 


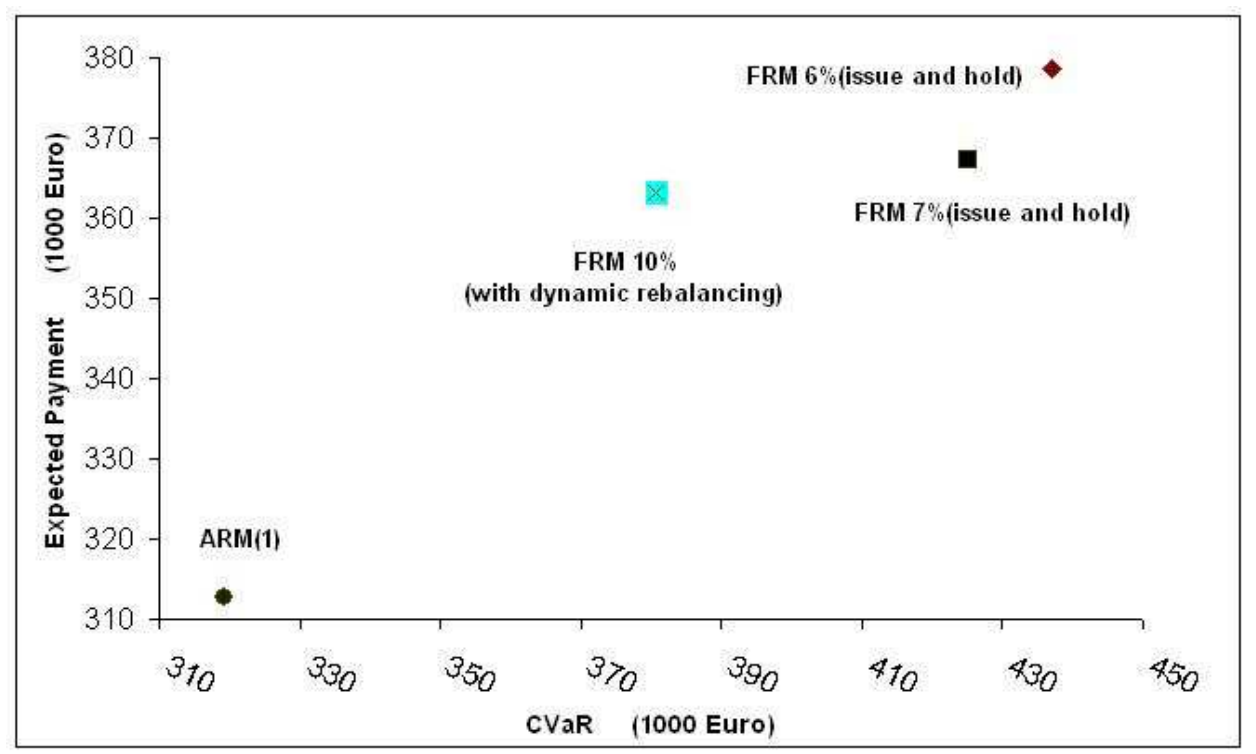

Figure 2: Expected payment and risk of payments (measured by Conditional Value-at-Risk, CVaR) for Fixed (FRM) and Adjustable (ARM) Rate Mortgages in the Danish mortgage market during the period 1995-2005.

The same conclusion is further highlighted from the analysis of the historical performance of mortgage loans in the Danish market during the period 1995-2005. Figure 2 shows the mean payment and the risk of the payment for various typical mortgages during this period. Risk is measured by the Conditional Value-at-Risk (CVaR) at the $90 \%$ confidence level, see, e.g., Rockafellar and Uryasev (2000) or Jobst and Zenios (2001). The differences in mean payments and CVaR, coupled with the negative correlation of the FRM and ARM payments suggest that interest rate risk can be diversified by holding portfolios of mortgages.

The structuring of diversified portfolios is the topic of this paper. But first some more explanations are in order for the operations of the Danish mortgage market.

\section{Some explanations on Danish mortgages}

The Danish mortgage banks are highly specialized institutions whose line of business is, first, to collect the investments from the investors of mortgage backed securities, and, second, to pool the investments together and issue mortgage loans to house buyers. The great volume of housing trade-the outstanding mortgage debt corresponds to one half of the gross domestic product of the country - the efficiency of the one-stop-shop process of mort- 
gage origination by specialized banks, together with a 200-year history of no default from the mortgage banks ${ }^{1}$ result in cheap loans for prospective house buyers. As investors are not exposed to default risk the Danish mortgage backed securities are rated AAA, and banks simply add to the market bond yields a markup rate which currently stands at $0.55 \%$.

A unique feature to the Danish mortgage market is the "balance principle" prescribing that the payments made by the mortgagor are exactly the payments received by the investor. In effect, Danish mortgagors are trading directly mortgage bonds and may exercise all the options. A Danish FRM has a call option typically with strike price at 100 and a buy-back delivery option embedded on the underlying bonds. This has in particular an impact on loans with long maturities, as small movements in interest rates result in big movements in the prices of FRMs and, hence, have a direct impact on the amount of outstanding debt for the Danish mortgagor.

Until 1995 FRMs were the only kind of mortgage backed securities which were traded in the Danish market. Since then the mortgage market has been growing fast and a number of new products have been introduced. The two most popular products have been the adjustable rate mortgage loans with varying adjustment intervals, and capped ARM loans where the interest rate cannot grow higher than a predetermined level.

All these loans can be issued with Interest-Only payments for a grace period of up to 10 years, although after 10 years it is possible to refinance the loan with another 10 years of I-O payments and as a result the outstanding debt is not being reduced during this period. ${ }^{2}$

The features of either FRM or ARM, together with the flexibility for refinancing the loans, imply that the total payments on the mortgage during the life of the loan is highly uncertain. While a mortgage owner will finance a loan in ways that are consistent with his or her short term financial capabilities, in the long run the payments made and the outstanding debt will be determined by the changing interest rates. A simulation model can be used to project the total payments, including the value of the outstanding debt if the loan is refinanced before maturity; see Mulvey and Zenios (1994) on the use of simulation models for capturing correlations of fixed income securities. Payment projections are made based on an underlying interest rate process - we use a variation of the Vasicek model in our work; see Appendix A-for all types of loans. The same process is also used to estimate the mortgage security market price for the outstanding debt and to determine the exercise of any options. The result is a distribution of net payments for

\footnotetext{
${ }^{1}$ House owners may fail to pay their liabilities, but there has yet not been an incident of default when it comes to payments to investors via the mortgage banks.

${ }^{2}$ This practice has been challenged in the article by the Real Estate Center mentioned above, who questions whether rolling over debt over long horizons could be a ticking time bomb for the mortgage markets.
} 
different types of loans that can then be used to combine loans and obtain an optimized, diversified, portfolio. The simulation results for FRM and ARM given next further highlight the potential diversification effects of optimized portfolios.

\subsection{Fixed rate mortgages}

A FRM pays a fixed annual rate for the duration of the loan-normally 15, 20 or 30 years. In addition to the fixed rate there is also a price associated with a FRM, which is based on the amount paid by the investor to the mortgage bank upon loan origination. In particular, the interest rate and principal payment calculations are not based on the amount paid by the investor, but on the face value of the FRM. For example if the price of a FRM is 96.8 then for every 96.8 EUR that the mortgagor receives he will owe the investor 100 EUR.

As a result, although the interest rate payments on a FRM are fixed the overall payment is not constant due to the fact that the price of a FRM changes with the general level of interest rates change and the Danish mortgagor has a buy back delivery option on the FRM, which means that the mortgage can be prepaid at any time at the prevailing market price. Hence, unless the loan is kept until maturity - an unlikely situation - the borrower does not know with certainty the overall payments. This situation is illustrated using simulations in Figure 3 (top), for a 30-year 3\% FRM, which is prepaid after six years.

It is worth pointing out that, to our knowledge, no mortgage banks outside Denmark offer this buy back delivery option. In all other cases we are aware of, should the mortgagor wish to prepay the mortgage loan then payment is due of the original loan, or any remaining part thereof. Most mortgage banks across the world of course offer a call option, so the mortgagor may prepay the mortgage at a predetermined price, usually par. The buy back delivery (call) option of the Danish mortgages introduces an asymmetry in the payment distribution which is illustrated in Figure 3 (bottom) for a 30year $4 \%$ FRM with a price close to strike, when it is also prepaid after six years under different interest rate scenarios.

Comparing the payments of the two FRMs we observe that the FRM with the price closest to par has a smaller volatility of payments but a higher mean. Increased volatility is the price to pay for the upper bound on the payment. Some mortgagors are willing to pay higher mean payments in order not to worry about very high payments that might occur if the initial price of the FRM is below par and interest rates drop. Others may prefer the low original payment today to get into a new home, in expectation of higher income in the future. As a rule of thumb house buyers are not advised to issue FRM with prices below 95 . 

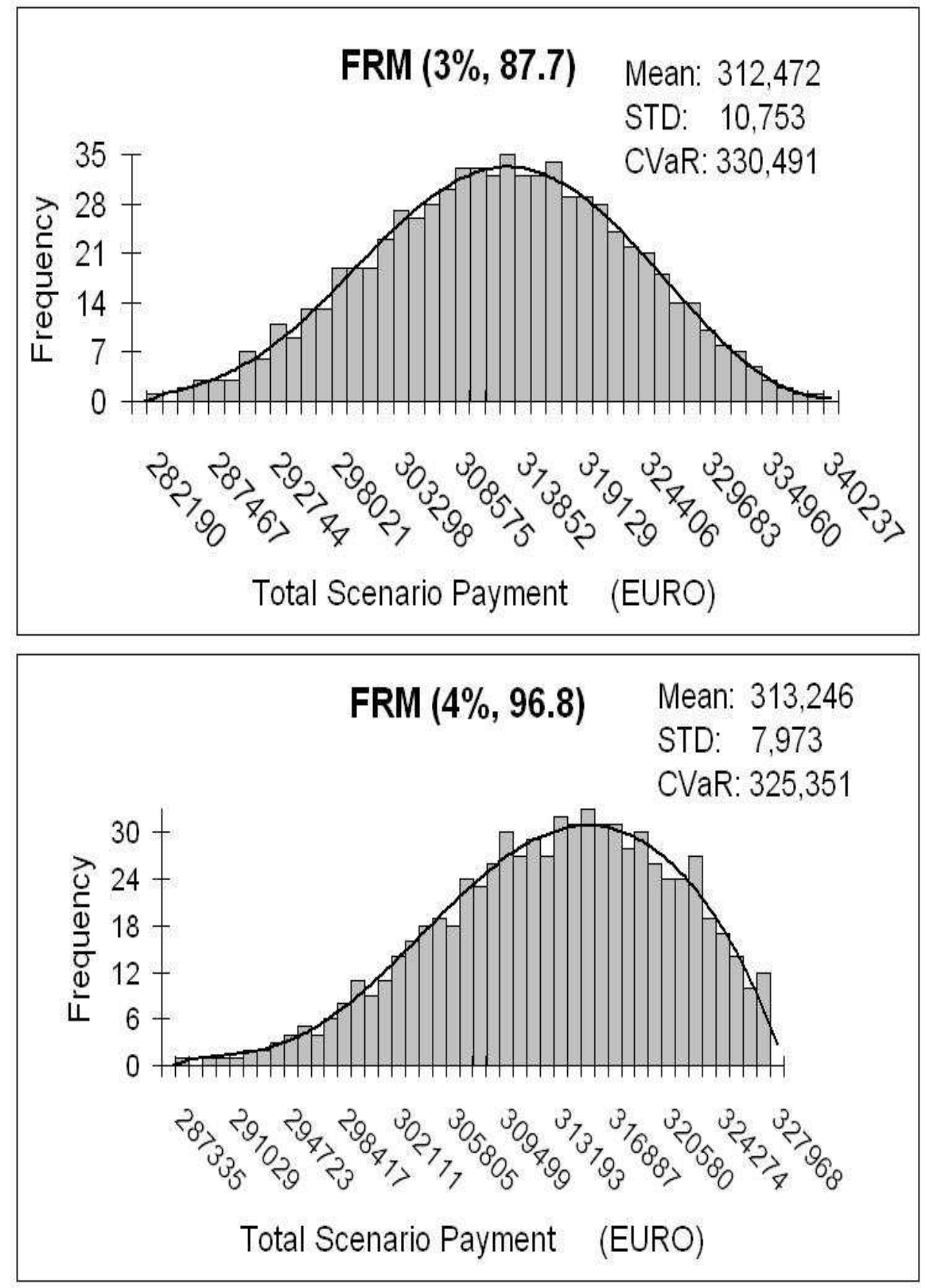

Figure 3: Distribution of total payments, including interest payments and principal prepayment after six years, of 30-year fixed rate mortgages with different rates: $3 \%$ (top) and $4 \%$ (bottom). 


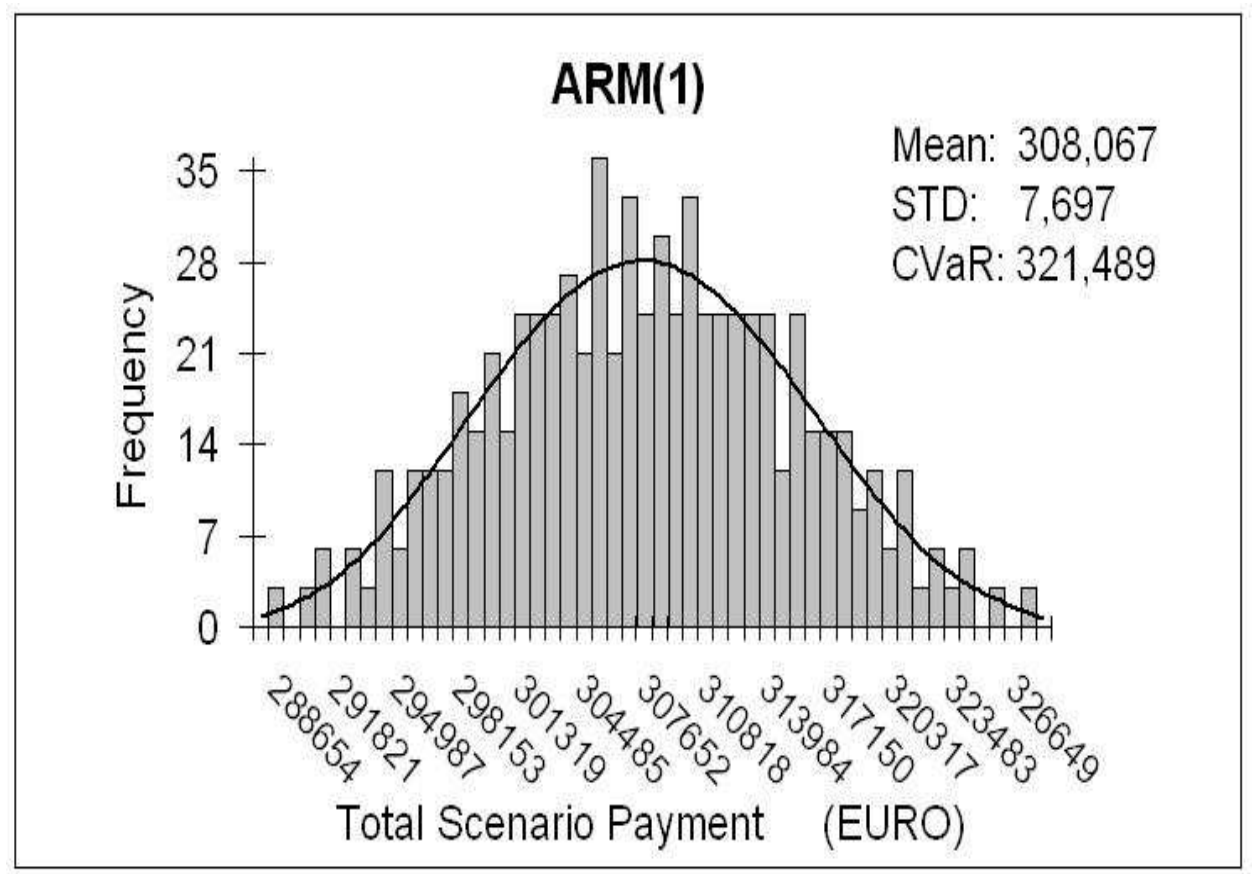

Figure 4: Distribution of total payments, including interest payments and principal prepayment after six years, of a 30-year adjustable rate mortgage $\operatorname{ARM}(1)$ with annual adjustments.

\subsection{Adjustable rate mortgages}

Adjustable rate mortgages have both a varying rate and a varying price and the distribution of Figure 4 illustrates the net payments of an annually adjusted 30-year ARM(1) over a holding period of six years.

For an ARM(1) with annually adjustable rate the price is almost constant and close to par, but as the re-adjustment period increases - in Denmark up to 10 years for $\operatorname{ARM}(10)$ - the price may vary considerably as the general level of interest rates changes similarly to a FRM with maturity of 10 years. In contradistinction to FRMs, however, most ARMs have no embedded call options and their price might increase to such extremes which makes it impossible for the mortgagor to prepay the loan, should he decide to quit the loan before the horizon of the fixed rate term in question.

The interaction between rates and prices, and the uncertainty surrounding the timing for selling the house-due to changing family conditions-makes it difficult to choose an ARM for a particular mortgagor. Nielsen and Poulsen (2004) and Rasmussen and Clausen (2006) proposed models for structuring mortgage loans for homeowners. However, these models focus on a single product and do not explicitly introduce a risk measure that bring to the 
surface the diversification issues. A comparison of the distribution of payments for a 30-year ARM(1) with annual adjustments and a 30-year 4\% FRM shown in Figure 5, together with the negative correlations of FRM and ARM shown earlier, further highlights the fact that a combination of both types of mortgages should reduce both the average payment and the volatility of payments, and in addition impose a limit on the upside potential for high payments in the future.

A model for diversifying mortgage loans is introduced next.

\section{A diversification model}

The optimization model specifies portfolios that trade off the net present value of the total mortgage payment against a risk measure of these payments. The risk measure we adopt in this paper is that of Conditional Value-at-Risk (CVaR) that has both the theoretical properties of "coherence" (Artzner et al., 1999) and is also well suited for diversifying portfolios of assets with skewed distributions (Jobst and Zenios, 2001).

We are given a set of scenarios $l \in \Omega$ obtained from the simulation model (see Appendix A) and a set of mortgage loans $i \in U$, and the following parameters generated by the simulation model for each scenario:

$p^{l}$, the probability associated with scenario $l$,

$d^{l}$, discount factor under scenario $l$,

$K_{i}^{l}$, the call price of loan $i$ under scenario $l$,

$r_{i}^{l}$, coupon rate for loan $i$ under scenario $l$.

$C F_{i}^{l}$, the net present value of payments from one unit of loan $i$ under scenario $l$, including interest and principal payments as well as any fees,

$P P_{i}^{l}$, the net present value of prepayments from one unit of loan $i$ under scenario $l$ including any retirement of the debt at prevailing market prices.

The following are given input data, relating to features of the problem:

$I A$, the initial amount to be borrowed in order to finance the house purchase,

$P_{i}$, price of loan $i$ at origination time,

$c$, variable transaction costs (in percentage),

$c_{f}$, fixed costs associated with mortgage origination or refinancing. 

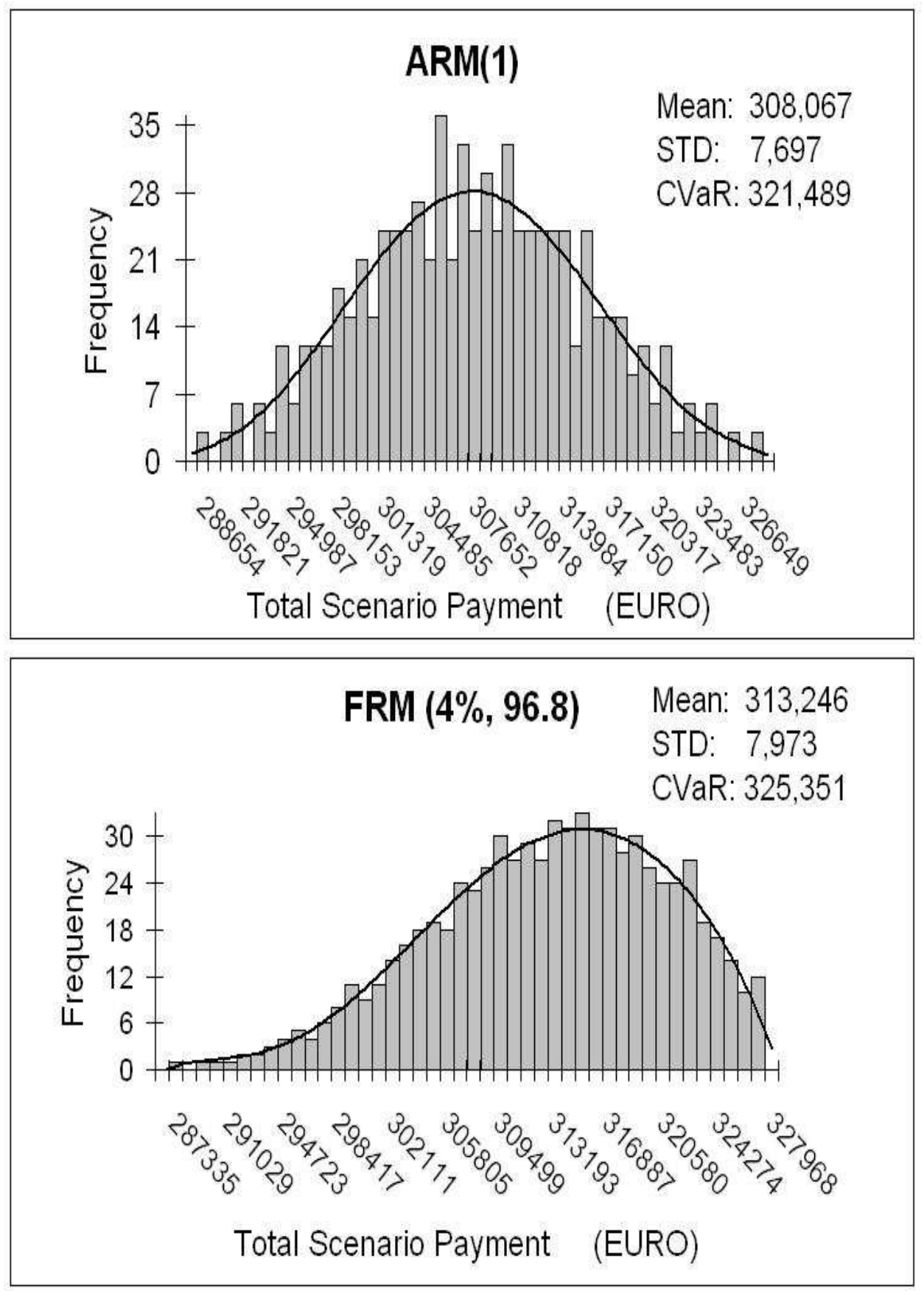

Figure 5: Comparing the distribution of total payments, including interest payments and principal prepayment after six years, of a 30-year adjustable rate mortgage with annual adjustments and a 30-year fixed rate mortgage. 
Finally, we define the model variables:

$y_{i}$, units sold of loan $i$,

$\zeta$, Value-at-Risk (VaR) at the $100 \alpha \%$ confidence level,

$\operatorname{CVaR}(y ; \alpha)$, conditional Value-at-Risk of a portfolio with loans $y=\left(y_{i}\right)_{i \in U}$ at the $100 \alpha \%$ confidence level,

$y_{+}^{l}$, amount of payment under scenario $l$ exceeding the VaR level $\zeta$,

$Z_{i}=\left\{\begin{array}{l}1 \text { if any amount of loan } i \text { is originated. } \\ 0 \text { otherwise. }\end{array}\right.$

The optimization model can now be formulated as follows using the linear programming formulation of Rockafellar and Uryasev (2000), where we use $\lambda$ to denote the degree of risk aversion, ranging from 1 for high risk aversion and 0 for no risk aversion (see also Zenios, 2006):

$$
\begin{aligned}
& \text { Minimize } \quad(1-\lambda)\left[\sum_{i \in U} \sum_{l \in \Omega} p^{l}\left(C F_{i}^{l}+P P_{i}^{l}\right) y_{i}\right]+\lambda \operatorname{CVaR}(y ; \alpha) \\
& \text { subject to } \quad \sum_{i \in U} P_{i} y_{i} \geq I A+\sum_{i \in U}\left(c y_{i}+c_{f} Z_{i}\right) \\
& M Z_{i}-y_{i} \geq 0 \quad \text { for all } i \in U \\
& y_{+}^{l} \geq\left[\sum_{i \in U}\left(C F_{i}^{l}+P P_{i}^{l}\right) y_{i}\right]-\zeta \text { for all } l \in \Omega \\
& \operatorname{CVaR}(y ; \alpha)=\zeta+\frac{\sum_{l \in \Omega} p^{l} y_{+}^{l}}{1-\alpha} \\
& y_{i}, \zeta, y_{+}^{l} \geq 0, \quad Z_{i} \in\{0,1\}
\end{aligned}
$$

The objective function (1) trades off the net present value of total payments (including prepayments) against the risk measure as given by CVaR. Constraint (2) makes sure that we originate enough loans to buy the house at a cost $I A$ and pay any transaction costs and the fixed mortgage origination costs. Constraint (3) sets the binary variable $Z_{i}$ to 1 indicating that fixed mortgage origination costs need to be incurred, if any amount of loan $i$ is chosen in the portfolio of loans, where $M$ is a large constant to account for the maximum allowable loan.

Constraints (4) and (5) together define the CVaR of the portfolio at the $100 \alpha \%$ confidence level, see Rockafellar and Uryasev (2000) or Zenios (2006). Finally we have the non-negativity constraints (6).

We applied this model to build diversified portfolios of mortgages. First, simulations are employed to develop scenarios of cashflow payments and 


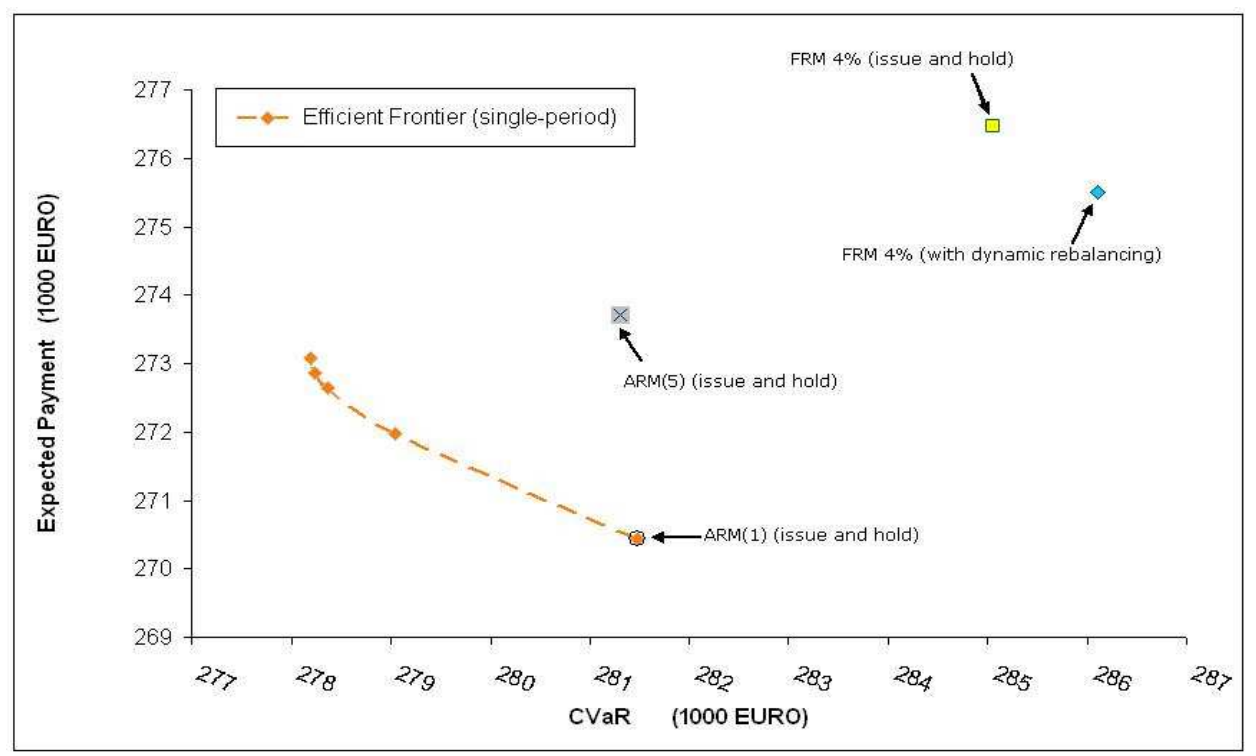

Figure 6: The efficient frontier of diversified portfolios of mortgage loans is shown together with performance of individual mortgages in the mean/CVaR space, and the performance of dynamic strategies for rebalancing a single mortgage loan.

outstanding principal for both FRM and ARM and then the optimization model is run on the set $\Omega$, and for different values of the risk aversion parameter $\lambda$. The results are shown in Figure 6, together with the performance of the individual mortgage loans available to our investor; the benefits from the diversified portfolio become apparent. We observe that the ARM(1) appears as the sole mortgage on the portfolio of only the least risk averse investors, but as risk aversion increases the portfolios diversify into $\operatorname{ARM}(5)$ and FRMs as well.

We go a step further, however, and show on the same figure the performance of the loan of a homeowner who follows a dynamic strategy of rebalancing his or her single FRM as market conditions change. This is clearly a better strategy than issuing and holding a single mortgage throughout and it is, indeed, the strategy pursued by most homeowners who chose FRMs. But even so, we observe from the results of this figure that the dynamic policy reduces the expected payments, but it does so by assuming higher risks, and it is dominated by the diversified portfolios.

Here, we may rest our case, having demonstrated the validity of the diversification approach for portfolios of mortgage loans. However, an interesting question has been raised that prompts us to further modelling investigations: If a dynamic strategy of rebalancing a single mortgage loan has some advantages over the issue-and-hold strategy, could it be the case that a dy- 
namic portfolio optimization model would do even better than the model of this section that is defined over a single period, with allowing the possibility of dynamic rebalancing at some future intermediate stages? The answer is affirmative as we see in the next section.

\section{Taking a long term perspective}

The long time horizon of the mortgage decision, and the ability of the mortgage owner to rebalance the loan as market (or family) conditions warrant it, begs for the application of dynamic multi-period portfolio optimization strategies using multi-stage stochastic programming. Such programs have a long history in the optimization literature (see, e.g., Birge and Louveaux (1997) or Censor and Zenios (1997)) and have been gaining prominence in the risk management literature since the eighties (Ziemba (2003), Zenios and Ziemba (2006)). The extension of the model above into a multi-stage setting is developed in Rasmussen and Zenios (2006), where a five-period, four-stage model is developed allowing for refinancing the loan at years one, two, three and five, and maturity at year seven.

The application of the multi-stage model for optimizing diversified portfolios leads to significant improvements in performance as witnessed from the results of Figure 7, leading to the simultaneous reduction of both the expected net payments and the risk of the payments as measured by CVaR

The structure of the diversified portfolios obtained with both the singleperiod and the multi-stage model are shown in Figure 8. We observe that for investors with low risk aversion, ARMs is the predominant class of mortgage loans no matter which optimization model is used. However, as risk aversion increases we observe a gradual shift towards the class of FRMs and while this trend is common with both models there is significantly more reliance on FRMs for the investor using the multi-stage model. This is so, since with the multi-stage model we can rebalance the portfolio of FRMs at the appropriate time for each scenario. The optimal strategy recommended by the multi-stage model is essentially equivalent to synthesizing an ARM with optimal timing for rate re-adjustment at intermediate stages, at one, two, three or five years, depending on the scenario of interest rates. This finding points out that it is worth designing more complex ARM structures that will lock in a rate for pre-specified periods that may depend on the prevailing rates. To do so, however, a legal construct is required so that the synthesized ARM will be presented as a single loan. 


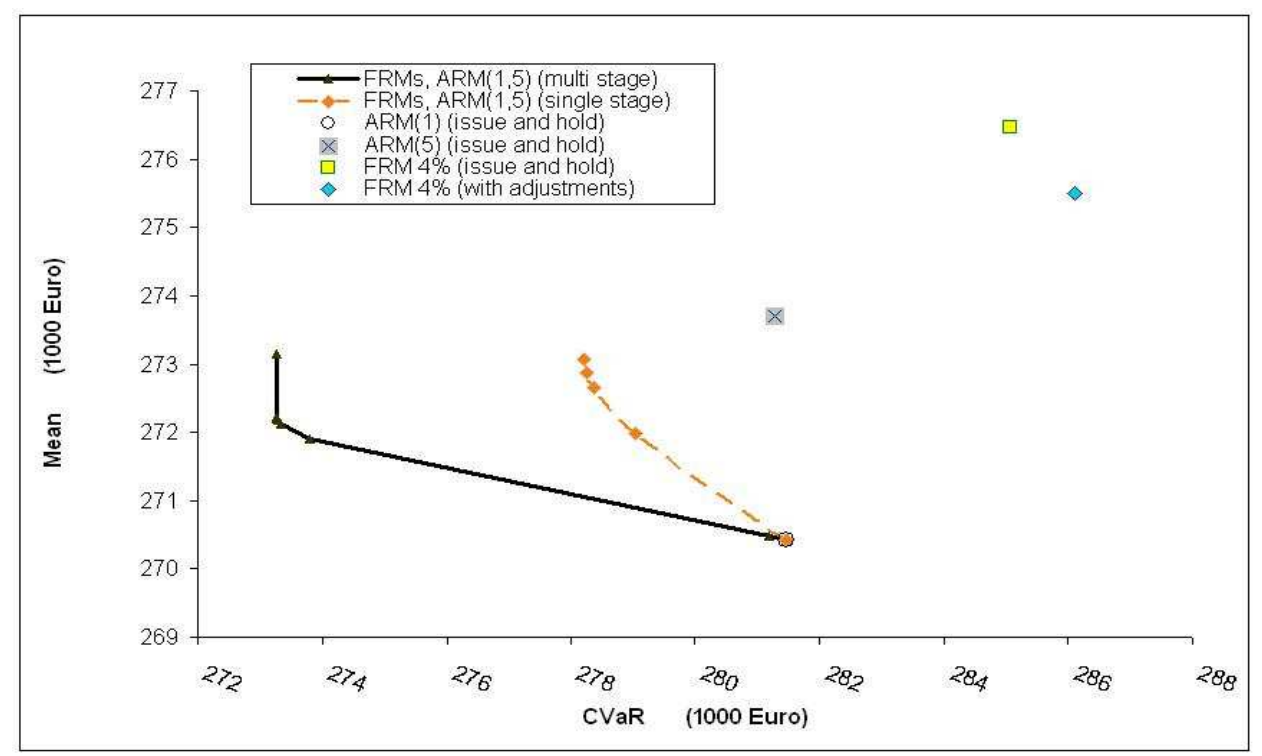

Figure 7: Significant improvements in the performance of diversified portfolios of mortgage loans are realized with the use of a multi-stage model over the single-period model.

\section{Two interesting observations}

Finally we use the model to offer answers to two questions that are often raised in the context of mortgage management.

\subsection{The effect of mortgage origination costs}

First, we consider the effect of fixed transaction costs for loan origination and the adverse effect this has in rebalancing mortgage loans. Indeed, the arguments against portfolios of loans of mortgages is based on the assumption that the origination costs will be prohibitively high. Mortgage origination costs, in Denmark, include a fee of $1.5 \%$ on the required loan paid to the bank upfront for all and any mortgage loans obtained from the bank, a $0.5 \%$ penalty for refinancing a loan with a different mortgage and a 300 EUR administration fee for originating every new mortgage. The largest of these fees (1.5\% on the loan amount) is a sunk cost, and does not affect our decision to refinance a mortgage, assuming we stay with the same bank. The rebalancing proportional cost of $0.5 \%$ is akin to the transaction costs for any asset management problem and it has been included in all our previous runs. What is left unexamined is the cost for originating new mortgages over and above the original loan. We run the portfolio optimization model with and without the 300 EUR mortgage origination costs. The results are shown 

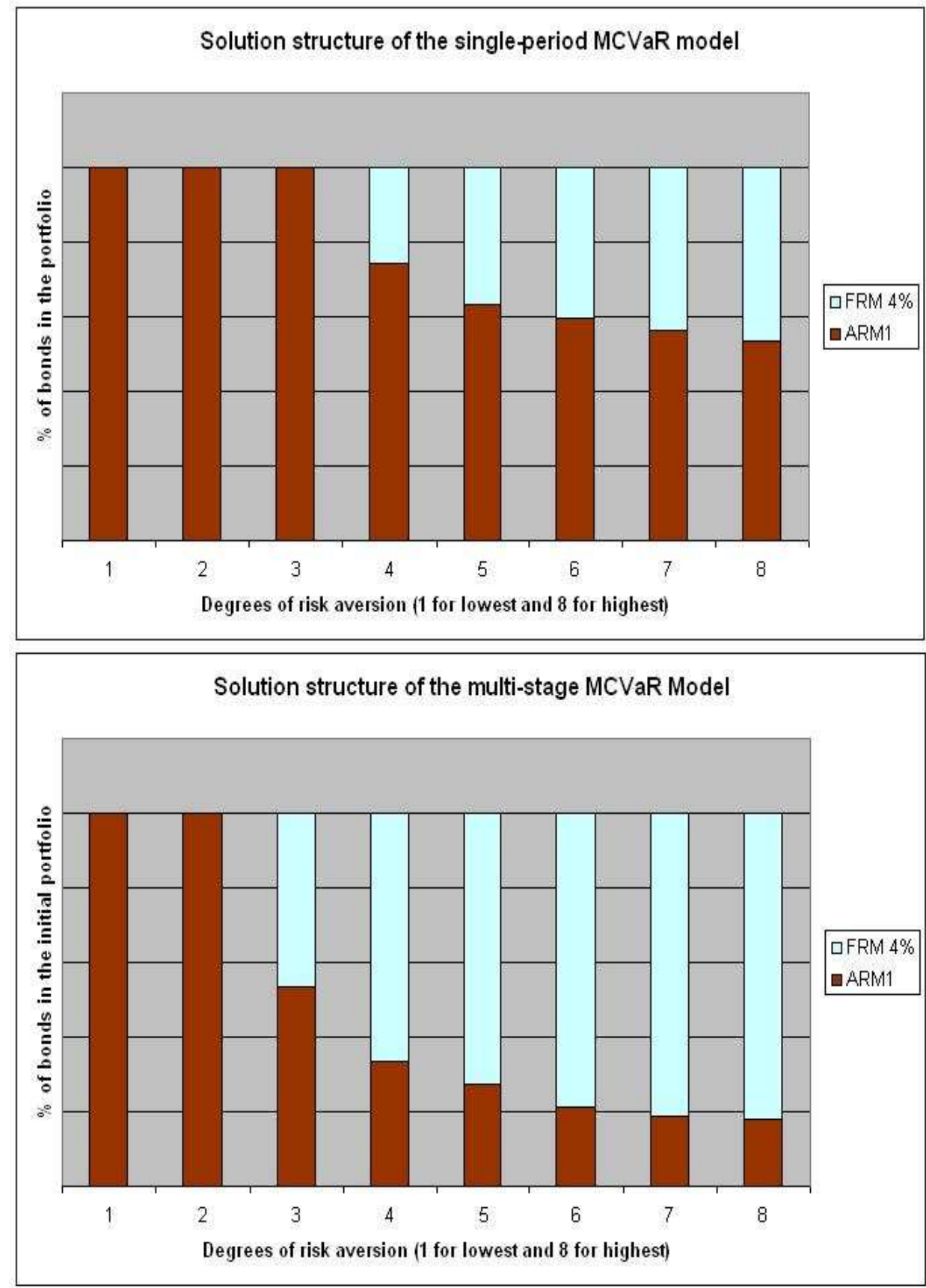

Figure 8: The composition of the diversified portfolio in the aggregate categories of fixed and adjustable mortgages when using both the single-period and the multi-stage models. 


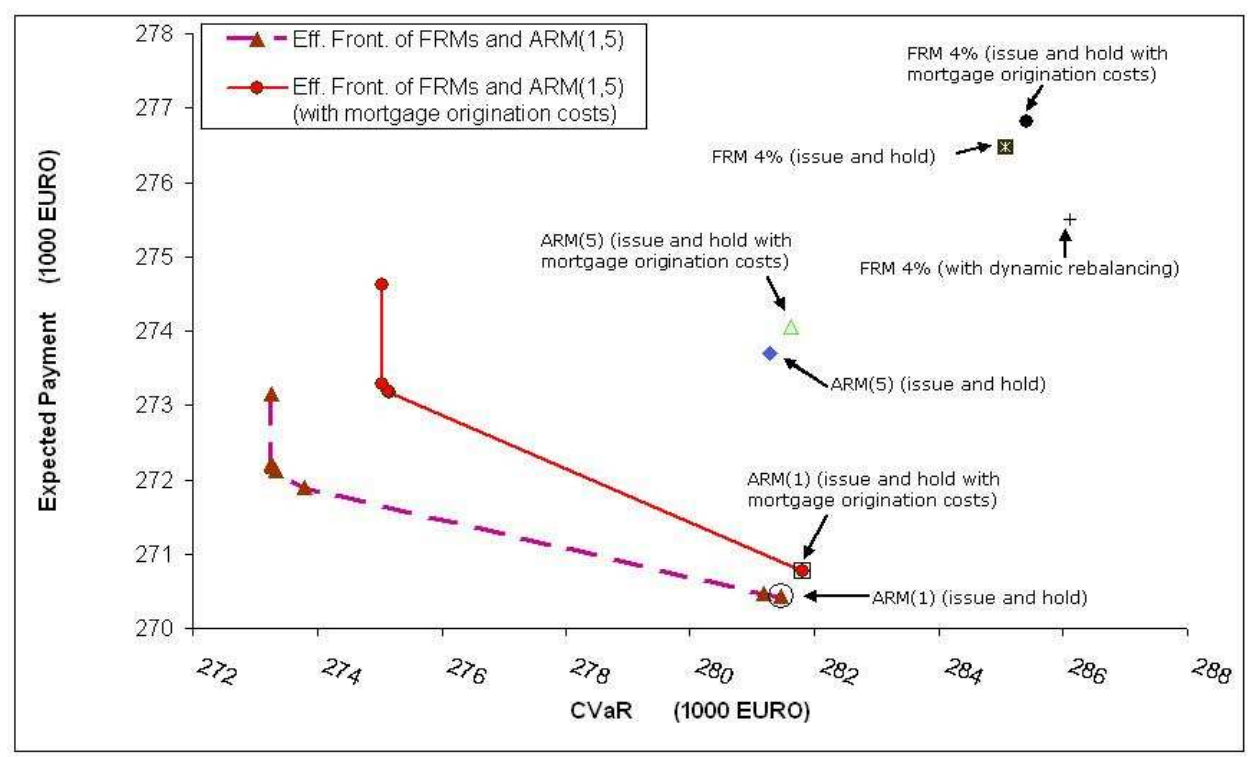

Figure 9: Efficient frontiers of diversified portfolios of loans with and without the mortgage origination costs.

in Figure 9. While we note that the performance of the diversified portfolio deteriorates when origination costs are included, it is still the case that they do much better in mean/CVaR space than any of the individual mortgages, and they also outperform the dynamic strategy of rebalancing a single FRM. Hence, loan diversification pays even when accounting for the higher costs of originating multiple loans.

\subsection{Designing new mortgage products}

Armed with the portfolio diversification models we can analyze the effect of new mortgage products on the homeowners' portfolios. This has clear implications for the introduction of new products in the market.

Naturally, as we add more products in the market the diversified portfolios will improve in performance. Or, at least, they will not perform worse as the optimization model will simply ignore any new products that do not contribute to the diversification. Indeed, Figure 10 clearly shows the improvements in efficient frontier as new instruments are added in the universe of mortgage backed securities, although the improvements are diminishing when adding more than three new securities.

What happens, however, if a bank wishes to issue only one type of $\operatorname{ARM}(t)$ with some to-be-determined period $t$ for rate readjustment, to complement a diversified portfolio of FRM and ARM(1)? We run the model by introducing- 


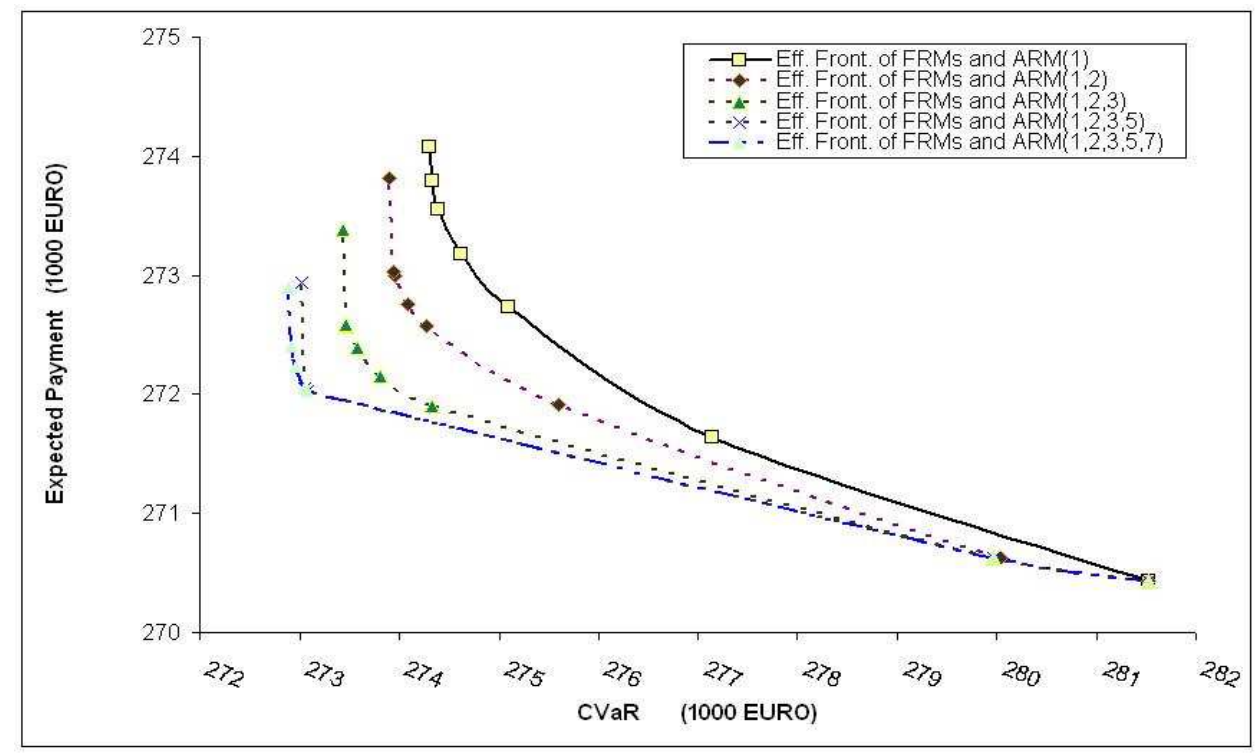

Figure 10: Expanding the universe of mortgage loans available to homeowners improves the performance of diversified portfolios, although the improvements come at diminishing rate when adding more than three securities.

one at a time- $\operatorname{ARM}(2), \operatorname{ARM}(5)$ and $\operatorname{ARM}(7)$. The results are shown in Figure 11, where we observe significant improvements in the performance of the diversified portfolios when we add an $\operatorname{ARM}(2)$ or $\operatorname{ARM}(5)$ to a portfolio with FRM and ARM(1), but things would deteriorate for almost all levels of risk aversion if an $\operatorname{ARM}(7)$ were introduced instead. This analysis provides guidance as to the best mortgage products to be introduced, to maximize the diversification benefits for the homeowners.

\section{Conclusions}

We have shown that well diversified portfolios of mortgage loans can better serve the needs of homeowners, in both financing the purchase of a home and staying within acceptable risk profiles. This conclusion is robust in the sense that it holds true even in the presence of transaction costs and for short and long horizons alike. From the models developed we have seen that the multi-stage stochastic programming approach is particularly well suited for this type of problems. However, even a single-period model such as the mean/CVaR optimization that has been gaining widespread acceptance in risk management serves well the needs of this problem. The models also shed some insights on the introduction of new mortgages in the market.

Finally a word on potential extensions that are possible with the modelling 


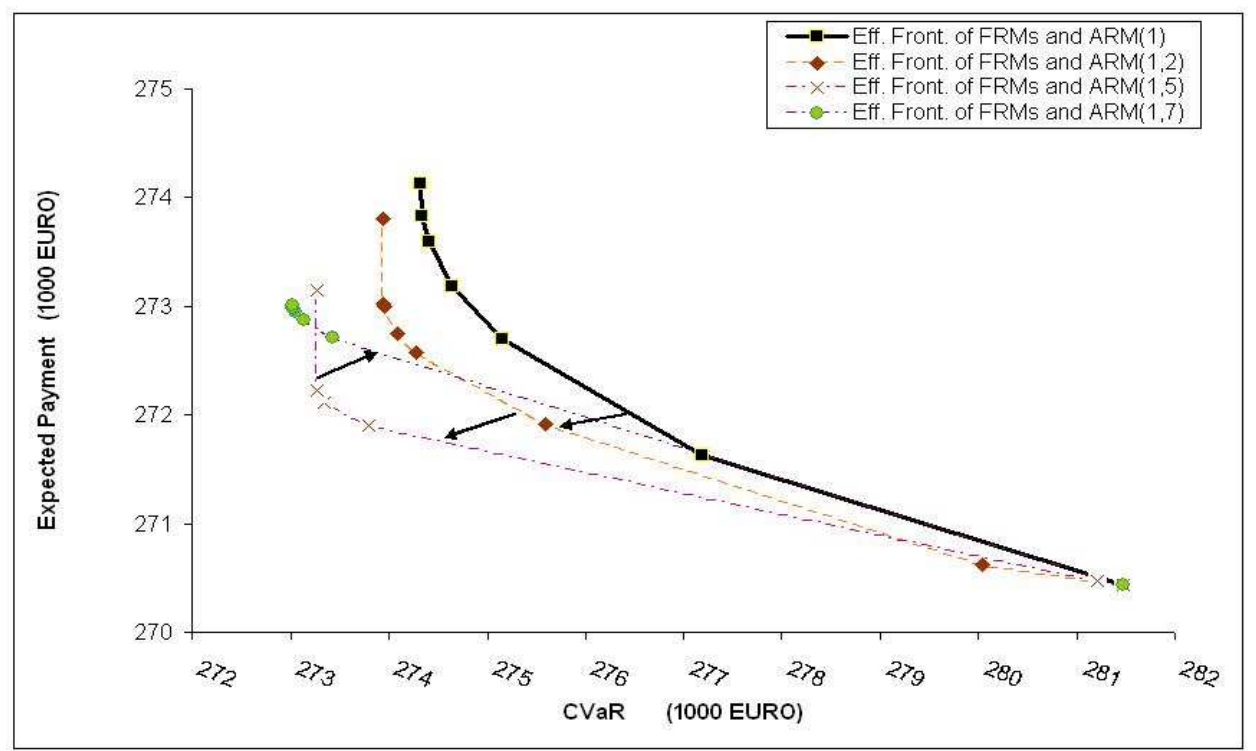

Figure 11: Designing new mortgage loans: Adding new products to the existing portfolio has the optimum positive impact for an $\operatorname{ARM}(2)$ and $\operatorname{ARM}(5)$ but the diversification effects are diminished for $\operatorname{ARM}(7)$.

setup we introduced. In this paper we only considered the interest rate risk. However, the scenario tree can be extended to represent house price and income dynamics in order to capture the wealth risk of the home owner as well.

\section{A The simulation model}

We use a variation of the Vasicek interest rate model (Jensen and Poulsen, 2002) as the underlying stochastic process to generate estimates of future short rates

$$
d r(t)=\kappa\left(\theta_{P}-r(t)\right) d t+\sigma d W_{p}(t),
$$

where $r(t)$ is the short rate, $W$ is a Brownian motion and $\kappa, \theta$ and $\sigma$ are model parameters controlling the height of the interest rate jumps, the long run mean level of interest rates and the volatility of the interest rates. The model is given under real-world probability measure $P$. This can be shifted to the risk free measure $Q$ using the transformation

$$
\theta_{Q}=\theta_{P}+\pi, \quad \pi \in \mathbb{R}
$$


where $\pi$ is the risk premium, so the Vasicek model under the risk free probability measure $Q$ becomes

$$
d r(t)=\kappa\left(\theta_{Q}-r(t)\right) d t+\sigma d W_{Q}(t) .
$$

The expected short rates are then found from

$$
E_{Q}[r(t)]=r_{0} \cdot \exp (-\kappa t)+\theta_{Q}(1-\exp (-\kappa t)) .
$$

We discretize this short rate process and estimate future rates and prices for mortgage backed securities using the pricing method of Nielsen and Poulsen (2004). 


\section{References}

[1] P. Artzner, F. Delbaen, J-M. Eber, and D. Heath. Coherent measures of risk. Mathematical Finance, 9:203-228, 1999.

[2] J.R. Birge and F. Louveaux. Introduction to Stochastic Programming. Springer, Heidelberg, 1997.

[3] Y. Censor and S.A. Zenios. Parallel Optimization: Theory, Algorithms, and Applications. Series on Numerical Mathematics and Scientific Computation. Oxford University Press, New York, NY, 1997.

[4] B. Jensen and R. Poulsen. Transition densities of diffusion processes: Numerical comparison of approximation techniques. Journal of Derivatives, 9(4):18-32, 2002.

[5] N.J. Jobst and S.A. Zenios. The tail that wags the dog: Integrating credit risk in asset portfolios. Journal of Risk Finance, pages 31-43, Fall 2001.

[6] J.M. Mulvey and S.A. Zenios. Capturing the correlations of fixed-income instruments. Management Science, 40:1329-1342, 1994.

[7] S.S. Nielsen and R. Poulsen. A two-factor, stochastic programming model of danish mortgage-backed securities. Journal of Economic Dynamics and Control, 28:1267-1289, 2004.

[8] K.M. Ramsmussen and S.A. Zenios. A multistage model for optimizing diversification strategies of mortage loans. Working paper, HERMES European Center of Excellence on Computational Finance and Economics School of Economics and Management University of Cyprus, Nicosia, CY, 2006.

[9] K.M. Rasmussen and J. Clausen. Mortgage loan portfolio optimization using multi stage stochastic programming. Journal of Economic Dynamics and Control, 2006. (to appear).

[10] R.T. Rockafellar and S. Uryasev. Optimization of conditional Value-atRisk. The Journal of Risk, 2(3):21-41, 2000.

[11] S.A. Zenios. Practical Financial Optimization: Decision making for financial engineers. Blackwell, Oxford, UK, 2006. (to appear).

[12] S.A. Zenios and W. Ziemba, editors. Asset and Liability Management. Handbooks in Finance. North-Holland, Amsterdam, The Netherlands, 2006. (to appear). 
[13] W.T. Ziemba. The stochastic programming approach to asset, liability and wealth management. The Research Foundation of AIMR, Association for Investment Management and Research, Charlottesville, VA, 2003. 